\title{
Phase Transformation and Work-hardening Behavior of Ti-based Bulk Metallic Glass Composite
}

\author{
Sung Hwan Hong, Jeong Tae Kim, Hae Jin Park, Young Seok Kim, Jin Man Park ${ }^{1}$, \\ Jin Yoo Suh ${ }^{2}$, Young Sang $\mathrm{Na}^{3}$, Ka Ram Lim³ ${ }^{3}$ Ki Buem Kim* \\ Department of Nanotechnology and Advanced Materials Engineering, Sejong University, Seoul 143-747, Korea \\ ${ }^{1}$ Global Technology Center, Samsung Electronics Co., Ltd., Suwon 443-742, Korea \\ ${ }^{2}$ High Temperature Energy Materials Research Center, Korea Institute of Science \& Technology (KIST), Seoul 136-791, Korea \\ ${ }^{3}$ Light Metal Division, Korea Institute of Materials Science (KIMS), Changwon 642-831, Korea
}

*Correspondence to:

Kim KB,

Tel: $+82-2-3408-3690$

Fax: +82-2-3408-4342

E-mail: kbkim@sejong.ac.kr

Received May 30, 2015

Revised June 24, 2015

Accepted June 24, 2015
In present work, work-hardening behavior of TiCu-based bulk metallic glass composite with B2 particles has been studied by systemic structural and mechanical investigations. After yield, pronounced work-hardening of the alloy was clearly exhibited, which was mainly related to the martensitic transformation as well as the deformation twinning in B2 particles during deformation. At the early plastic deformation stage (work-hardening stage), the stress-induced martensitic transformation from B2 phase to B19' phase and deformation-induced twinning of B19' phase was preferentially occurred in the around interface areas between B2 phase and amorphous matrix by stress concentration. The higher hardness value was observed in vicinity of interface within the B2 particles which are probably connected with martensitic transformation and deformation twinning. This reveals that the work-hardening phenomenon of this bulk metallic glass composite is a result of the hardening of $\mathrm{B} 2$ particles embedded in amorphous matrix.

Key Words: Bulk metallic glass composite, Work-hardening, Martensitic transformation, Deformation twinning

\section{INTRODUCTION}

Bulk metallic glasses (BMGs) have been highlighted as an accessible engineering material for advanced structural application due to their high strength, high hardness and large elastic limit (Inoue et al., 2003; Telford, 2004; Inoue \& Takeuchi, 2011; Tian et al., 2011). However, monolithic BMGs usually undergo inhomogeneous plastic deformation at room temperature caused by highly localization of shear stress, which has led to catastrophic failure of the alloys (Spaepen, 1977; Greer, 1995; Schuh et al., 2007). In order to overcome such a critical drawback of monolithic BMGs, the several attempts for improving the macroscopic plasticity of BMGs have developed bulk metallic glass composites (BMGCs) with reinforcements, e.g., ductile crystalline phases (Hays et al., 2000; Fan et al., 2006; Hofmann et al., 2008a; Qiao et al., 2011). Macroscopic plasticity of the BMGCs was induced by formation and propagation of multiple shear bands from strong interaction between shear bands and reinforcements (Fan et al., 2002). Another way to improve the plasticity of the BMGCs is introducing the nano-scale structural and chemical heterogeneities in the metallic glass matrix (Das et al., 2005; Kim et al., 2006a; Zhu et al., 2010; Park et al., 2012). These heterogeneities were suggested as factors to govern the plasticity by controlling the initiation, multiplication and propagation of shear bands (Kim et al., 2006b; Lee et al., 2007;

This work was supported by the National Research Foundation of Korea (NRF) grant funded by the Korea government (Ministry of Science, ICT \& Future Planning) (No. 2013R1A2A2A05006550), Industrial Infrastructure Program for fundamental technologies (Project number: N0000846) funded by Ministry of Trade, Industry and Energy (MOTIE, Korea).

@ This is an open-access article distributed under the terms of the Creative Commons Attribution Non-Commercial License (http://creativecommons.org/licenses/by-nc/4.0) which permits unrestricted noncommercial use, distribution, and reproduction in any medium, provided the original work is properly cited.

Copyrights (C) 2015 by Korean Society of Microscopy 
Kim et al., 2008). Especially, among the BMGCs and ductile BMGs, the Ti-and Zr-based BMGCs containing ductile dendrite phases exhibited excellent plasticity (Hofmann et al., 2008b; Qiao et al., 2011). However, these BMGCs show a macroscopic work-softening with an occurrence of necking immediately after yield. A lack of work-hardening mechanisms can be considered as serious problem for engineering application of BMGCs.

Recently, it was reported that the CuZr-based BMGCs containing shape memory B2-CuZr phase show obvious plastic deformation and pronounced work-hardening behavior under compression, even in tensile test (Das et al., 2009; Pauly et al., 2009; Pauly et al., 2010). These excellent mechanical properties are mainly related with the martensitic transformation from austenite $\mathrm{B} 2-\mathrm{CuZr}$ phase to monoclinic B19'-CuZr phase during deformation. The stress-induced martensitic transformation in CuZ-based BMGCs can increase the rate of work-hardening and suppress early necking (Wu et al., 2010). More recently, TiCu-based BMGCs containing B2 phases were also developed through the fine compositional tuning from the $\mathrm{Ti}_{45} \mathrm{Cu}_{40} \mathrm{Ni}_{7.5} \mathrm{Zr}_{5} \mathrm{Sn}_{2.5}$ BMG having nano-scale chemical fluctuation (Kim et al., 2006a; Zhang et al., 2013; Hong et al., 2014) and compositional investigation in the ( $\mathrm{TiCu})-(\mathrm{TiNi})-(\mathrm{CuZr})$ pseudo-ternary system (Gargarella et al., 2014). These B2 phase-reinforced BMGCs also represent a strong work-hardening behavior and large plasticity identical to CuZr-based BMGCs. The workhardening rate and large plasticity of $\mathrm{TiCu}-$ and $\mathrm{CuZr}$-based BMGCs are extremely dependent on the volume fraction of B2 phases (Pauly et al., 2009; Gargarella et al., 2014). However, martensitic transformation on $\mathrm{B} 2$ particles after plastic deformation was not observed in $\mathrm{Ti}_{44} \mathrm{Cu}_{40} \mathrm{Ni}_{8} \mathrm{Zr}_{8-\mathrm{x}} \mathrm{Sn}_{\mathrm{x}}$ (with $\mathrm{x}=2,3$ ) BMGCs with B2 particles despite exhibiting a distinct work-hardening behavior with large plasticity (Zhang et al., 2013), which deviates from general mechanism of work-hardening behavior of BMGCs with B2 particles. Moreover, there is no systematic study about the mechanism of work-hardening behavior in Ti-based BMGCs with B2 particles. Therefore, it is noteworthy to explore the role of B2 particles in work-hardening behavior and martensitic phase transformation behavior of B2 particles in Ti-based BMGCs during deformation.

In order to investigate the influence of B2 particles on work-hardening behavior of Ti-based BMGCs, we selected the $\mathrm{Ti}_{45.3} \mathrm{Cu}_{39.5} \mathrm{Ni}_{7.8} \mathrm{Zr}_{4.9} \mathrm{Sn}_{2.5}$ BMGCs with strong workhardenability as well as large plasticity (Hong et al., 2014). In this manuscript, we report work-hardening mechanism of Tibased BMGCs with B2 particles via systemic microstructural and mechanical investigation for deformed sample with work-hardening state.

\section{MATERIALS AND METHODS}

$\mathrm{Ti}_{45.3} \mathrm{Cu}_{39.5} \mathrm{Ni}_{7.8} \mathrm{Zr}_{4.9} \mathrm{Sn}_{2.5}$ alloy (Hong et al., 2014) ingots were prepared by arc melting with elements purity of 99.9 at $\%$ or higher in an argon atmosphere. The ingot was remelted at least 5 times in order to achieve homogeneity. As-cast sample was prepared by suction casting into a cylindrical rod-shape $\mathrm{Cu}$ mold with diameters of $2 \mathrm{~mm}$ and $50 \mathrm{~mm}$ in length. In order to analyze the phase and structure of as-cast rod sample, X-ray diffraction (XRD, Rigaku-D/MAX-2500/ PC; Rigaku, Japan) with $\mathrm{CuK} \alpha$ radiation and transmission election microscope (TEM, Technai F20; FEI, USA) were used. Thin film specimens for TEM analysis were prepared by ion milling with liquid nitrogen cooling. The cross sectional microstructure of the rod sample was investigated by scanning electron microscopy (SEM, JEOL JSM-6390; JEOL, USA). The cylindrical samples with 2:1 aspect ratio for compression tests were prepared. Room temperature mechanical properties of the samples were tested under compressive mode at a strain rate of $1 \times 10^{-3} \mathrm{~s}^{-1}$. Structural characteristics of deformed samples were investigated using TEM. Nano-indentation experiments were conducted to measure the hardness of ascast and the deformed samples in the load-control mode with maximum load of $100 \mathrm{mN}$ at a constant loading/unloading rate of $3.3 \mathrm{mN} / \mathrm{s}$.

\section{RESULTS AND DISCUSSION}

Fig. 1 shows the XRD pattern, typical SEM backscattering electron (BSE) image, TEM bright field (BF) images and selected area electron diffraction (SAED) patterns of amorphous matrix and $\mathrm{B} 2$ particle of the as-cast $\mathrm{Ti}_{45.3} \mathrm{Cu}_{39.5} \mathrm{Ni}_{7.8} \mathrm{Zr}_{4.9} \mathrm{Sn}_{2.5}$ alloy. The XRD trace of as-cast sample exhibit typical for a BMGC characteristics in Fig. 1A. The crystalline peaks superimposed on the broad diffraction of amorphous phase are identified as the B2 phase. Fig. 1B reveals SEM BSE image obtained from cross section of as-cast sample which demonstrates a typical BMGC microstructure containing spherical crystalline particles with dark contrast (as indicated by white arrows) in brighten amorphous matrix. The spherical crystalline phases embedded in amorphous matrix are inferred the B2 phase based on XRD analysis in Fig. 1A. The B2 particles embedded in amorphous matrix exhibit the large size deviation, i.e., many small and large sized B2 particles. The average size of small and large B2 particles can be measured to be $1 \sim 15 \mu \mathrm{m}$ and 50 200 $\mu \mathrm{m}$, respectively. The TEM BF image shown in Fig. 1C obtained from as-cast sample show the B2 particle (dark contrast) embedded amorphous matrix (bright contrast). SAED patterns in Fig. 1D and E display a typical diffuse hallow ring corresponding amorphous phase and diffraction spots corresponding CsCl-type B2 phases, respectively. Furthermore, the superlattice (marked by white 

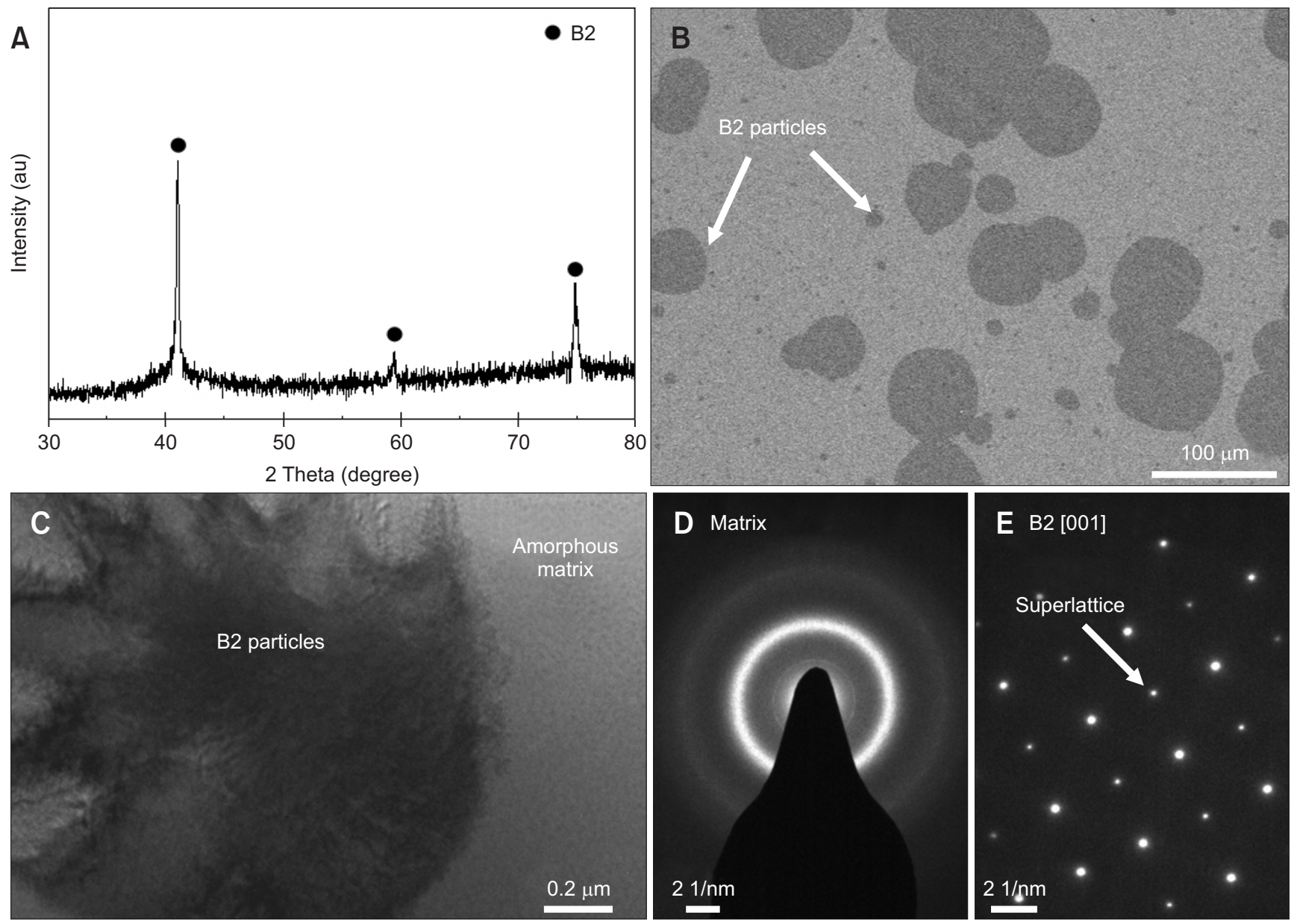

Fig. 1. X-ray diffraction pattern (A), scanning electron microscopy backscattering electron image (B), transmission election microscope bright field image (C), and selected area electron diffraction patterns (D, E) of as-cast alloy.

allow) of the $\{100\}$ plane of B2 phase is obviously visible. These results coincide with the XRD and SEM results in Fig. $1 \mathrm{~A}$ and $\mathrm{B}$. Based on these result, it is confirmed that the ascast $\mathrm{Ti}_{4.3} \mathrm{Cu}_{39.5} \mathrm{Ni}_{7.8} \mathrm{Zr}_{4.9} \mathrm{Sn}_{2.5}$ alloy is BMGC with $\mathrm{B} 2$ particles having size deviation, i.e., small $(1 \sim 15 \mu \mathrm{m})$ and large (50 200 $\mu \mathrm{m})$ particles.

Engineering stress-strain curve of the current BMGC under compressive loading are shown in Fig. 2, and the corresponding true stress-strain curve are exhibited in lower inset in Fig. 2. The current BMGC shows large plasticity of $13 \% \pm 2 \%$, yield strength of $1,645 \pm 25 \mathrm{MPa}$. The yield strength of current BMGC exhibits slightly lower than that ( $\sim 2 \mathrm{GPa})$ of monolithic BMG (not shown), which is caused by early deformation of softer B2 particles. For plastic deformation stage, pronounced work-hardening is clearly observed and the maximum strength are $1,900 \pm 25 \mathrm{MPa}$, respectively. The work-hardening exponent, $n$, can be estimated based on the Hollomon equation (Hollomon, 1945):

$$
S=K \varepsilon^{n}
$$

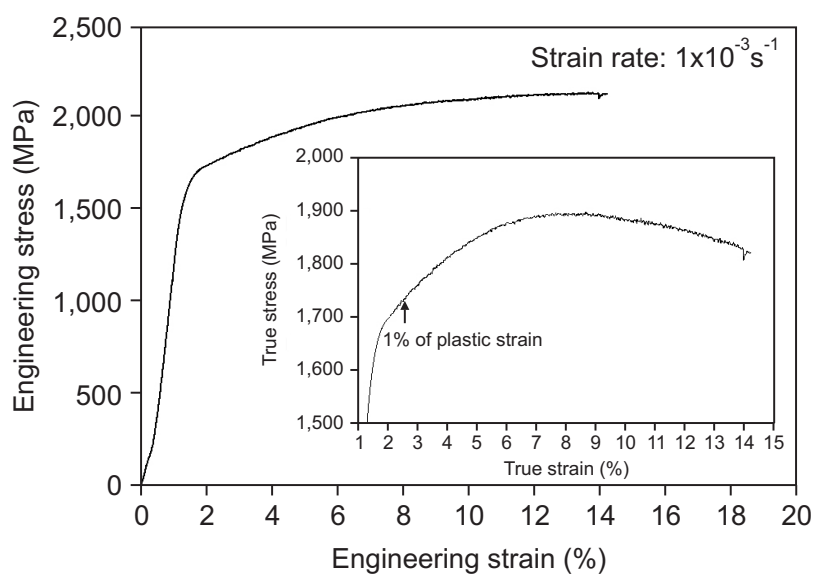

Fig. 2. Engineering stress-strain curve and corresponding true stressstrain curve (inset) of as-cast alloy.

where $S, K$ and $\varepsilon$ are the true stress, strength coefficient and true strain, respectively. The work-hardening exponent $n$ of the current BMGC was determined to be 0.126 , which is 
much higher than that of alloy steels widely used in structural applications (i.e., 30CrMnSiA: 0.063, 30CrMnSiNi2A: 0.091, 40CrNiMo: 0.066) (Zhang et al., 2006). Origins of the workhardening behavior of current BMGC will be discussed later on TEM and nano-indentation analysis of $1 \%$ plastically deformed (work-hardening stage) sample (marked by black arrow in inset).

In order to obtain deep insight into origin of work hardening behavior of current BMGC, the microstructural investigation of the $1 \%$ of plastically deformed sample was performed by TEM analysis. Fig. 3 shows the TEM BF images (Fig. 3A, E), high resolution (HR) TEM images (Fig. 3B-D, 3F-H) of large and small B2 particles obtained from the $1 \%$ plastically deformed sample and inset fast Fourier transformation (FFT) corresponding each HRTEM image. Fig. 3A exhibits the morphology of deformed large B2 particle embedded
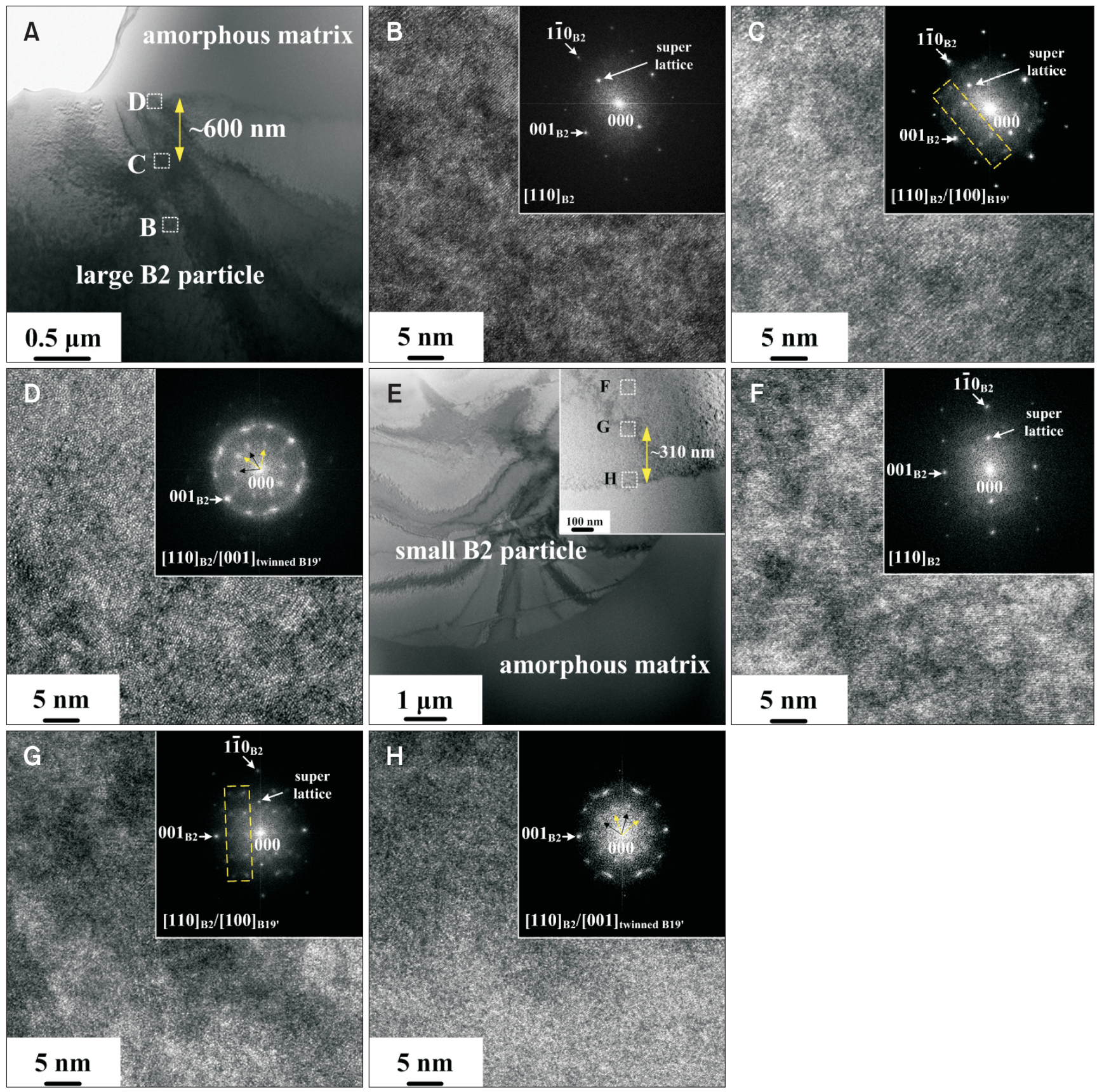

Fig. 3. Transmission election microscope bright field (TEM BF) images (A, E) of the large and small $\mathrm{B} 2$ particles obtained from $1 \%$ plastically deformed sample, high resolution TEM (HRTEM) images (B-D) and inset fast Fourier transformation (FFT) patterns corresponding 'B', 'C', and 'D' areas in Fig. 3A, HRTEM images (F-H) and inset FFT patterns corresponding ' $\mathrm{F}$, ' $\mathrm{G}$ ', and ' $\mathrm{H}$ ' areas in Fig. 3E. 


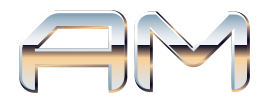

in amorphous matrix. Fig. 3B-D show HRTEM images corresponding to the ' $\mathrm{B}$ ', ' $\mathrm{C}$ ', and ' $\mathrm{D}$ ' areas in Fig. 3A. The inset FFT patterns obtained from HRTEM image in Fig. 3B is identified as [110] zone axis of the B2 phase. For more closed region $(\sim 600 \mathrm{~nm})$ in B2 particle with the interface between amorphous matrix and B2 phase, the inset FFT patterns of the corresponding HRTEM image in Fig. 3C presents feeble sub diffraction spots (marked by dotted yellow rectangle) superimposed in diffraction spots (marked by white arrow) corresponding [110] zone axis of B2 phase. These sub diffraction spots are indexed as [100] zone axis corresponding monoclinic B19' phase. This observation indicates that stress-induced martensitic transformation from B2 phase to B19' phase was occurred in closed regions to interface in B2 particle. Moreover, the inset FFT patterns of corresponding HRTEM image in Fig. 3D obtained from vicinity of interface region exhibits the [001] zone axis of twinned monoclinic B19' phase (marked by black and yellow arrows in center) superimposed on the [110] zone axis of B2 phase (marked by white arrows), which indicates occurrence of the stress-induced martensitic transformation as well as

A

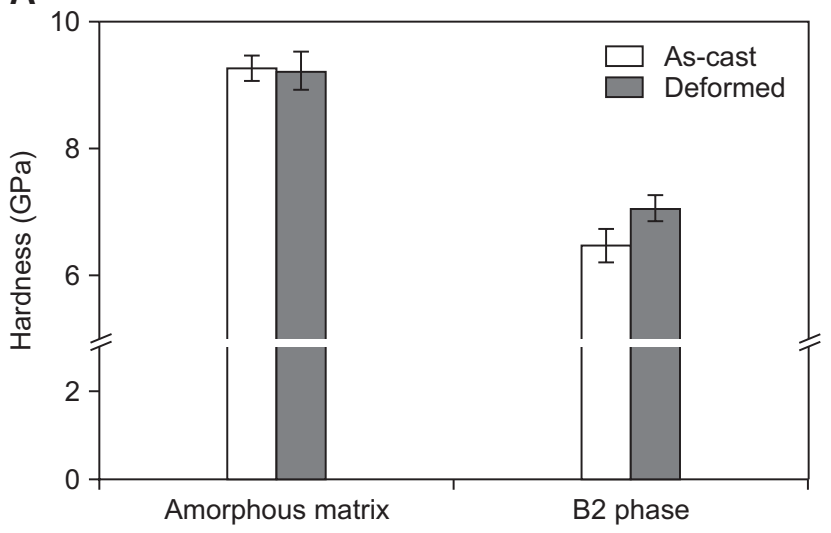

D

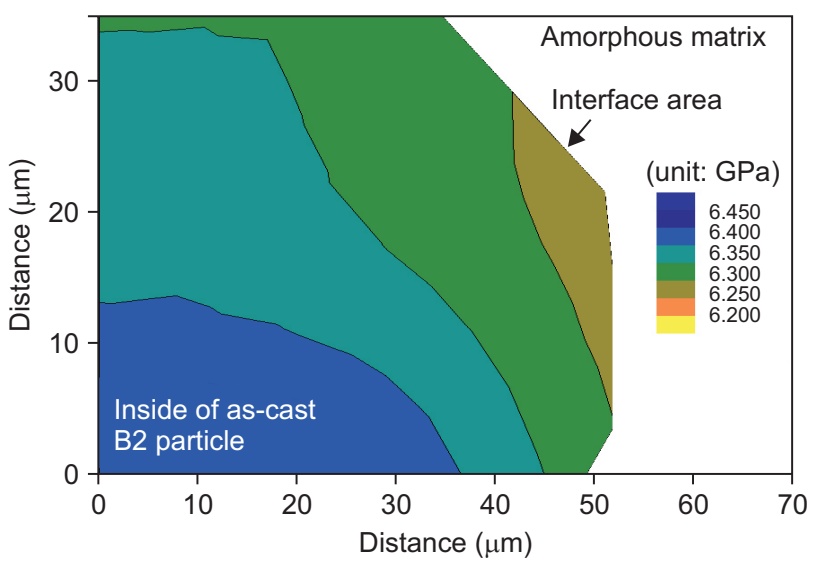

deformation-induced twinning of B19' phase. Fig. 3E exhibits the morphology of deformed small B2 particle embedded in amorphous matrix. Similarly to deformed large B2 particle, the inset FFT patterns corresponding HRTEM image in Fig. $3 \mathrm{~F}$ obtained from a distant region to interface (' $\mathrm{F}$ ' area in Fig. 3E) presents as the [110] zone axis of $\mathrm{B} 2$ phase, whereas the inset FFT patterns corresponding HRTEM images in Fig. $3 \mathrm{G}$ and $\mathrm{H}$ which is further closed region $(\sim 300 \mathrm{~nm})$ (' $\mathrm{G}$ ' and ' $\mathrm{F}$ ' areas in Fig. 3E) to interface between amorphous matrix and small B2 particle are confirmed as the [100] zone axis of B19' phase (marked by dotted yellow rectangle) and [001] zone axis of twinned B19' phase (marked by black and yellow arrow in center) superimposed on the [110] zone axis of B2 phase, respectively. This clearly demonstrates the occurrence of stress-induced martensitic transformation and deformation-induced twinning even in small B2 particles. From these observations, it is confirmed that the stressinduced martensitic transformation from B2 phase to B19' phase in both small and large B2 phases occurs in the closed regions to interface between amorphous matrix and B2 phases at the early stage of plastic deformation. Additionally,

B

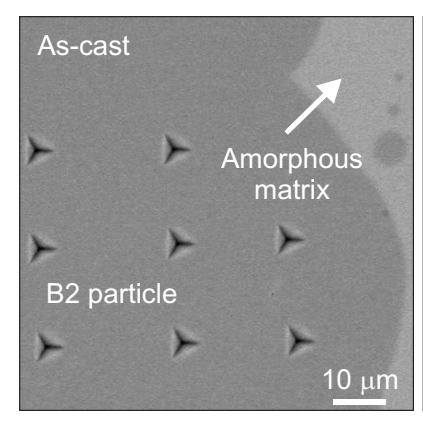

C

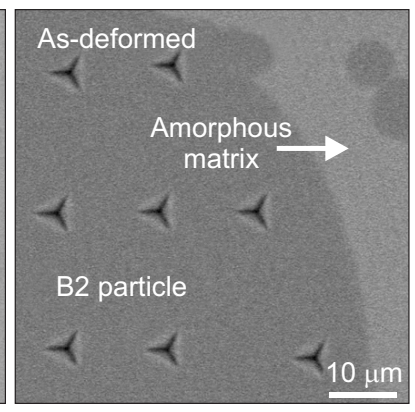

$E$

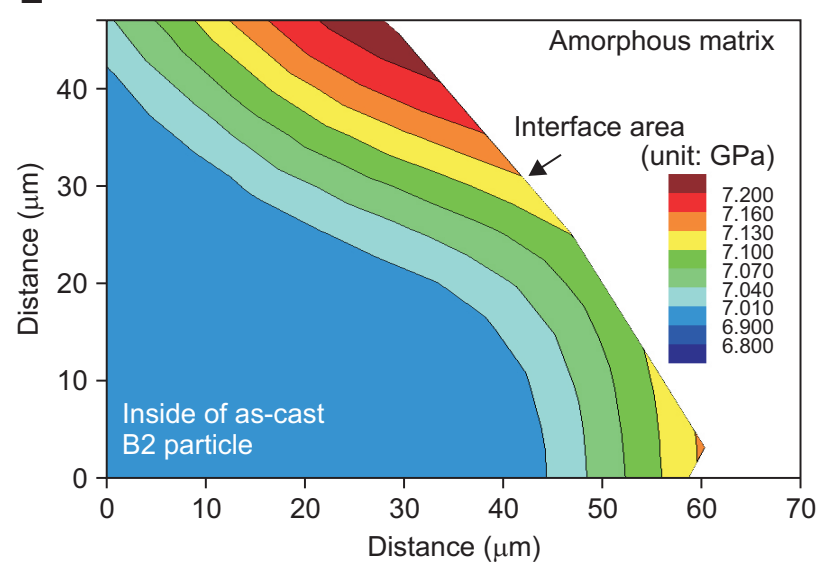

Fig. 4. Average hardness values (A) obtained from amorphous matrix and B2 particle, the indented morphologies (B, C) for B2 particle in as-cast and $1 \%$ plastically deformed sample, and the corresponding hardness distribution maps (D, E). 
the deformation induced twinning structure of B19' phase in the vicinity of interface reveals that the inhomogeneous distribution of stress was happened in B2 particles. It indicates that highly stress concentration is applied around interface areas rather than inside of B2 phase during early plastic deformation state, which can be considered as a result of lower elastic modulus of soft B2 phase than it of amorphous matrix (Zhang et al., 2013).

In order to understand origins of work-hardening behavior in current BMGC, nano-indentation technique was employed. It is known that the nano-indentation test combined with microscopic analysis is effective way to evaluate the relationship between micro-/nano-scale structural evolution and corresponding mechanical properties (Wu et al., 2010; Zhang et al., 2013; Kim et al., 2014; Lee et al., 2014a, 2014b). Fig. 4 shows the average hardness values of amorphous matrix and $\mathrm{B} 2$ particles obtained from as-cast and $1 \%$ of plastic deformed samples with the corresponding SEM images and hardness distribution maps of as-cast and deformed B2 particles. As shown in Fig. 4A, the hardness of deformed amorphous matrix is not changed comparing with it of ascast amorphous matrix. On the other hands, the deformed B2 particles exhibit higher hardness value than as-cast B2 particles. SEM images shown in Fig. $4 \mathrm{~B}$ and $\mathrm{C}$ show the nano-indentation morphologies of as-cast and deformed B2 particles and the corresponding hardness distributions within depending on the region of indented area of Fig. $4 \mathrm{~B}$ and $\mathrm{C}$ are displayed in Fig. 4D and E, respectively. There is no large difference of the hardness values within as-cast B2 particles while the higher hardness values are observed in the vicinity of interface within the deformed B2 particles. These results are probably connected with the plateau of the martensitic transformation from B2 phase to B19' phase and deformation twinning of B19' phase occurred by stress concentration around the interface areas as observed in Fig. 3. Based on these results, it is concluded that the work-hardening phenomenon after yield stage is a result of the hardening of the B2 particles into the amorphous matrix.

\section{CONCLUSIONS}

In the present work, the influence of $\mathrm{B} 2$ phase on workhardening behavior of Ti-based BMGC containing B2 particles was systemically investigated by micro-/nano-scale structural and mechanical investigation. The detailed investigation at early stage of plastic deformation (work-hardening stage) reveals that the stress-induced martensitic transformation from B2 phase to B19' phase within B2 particles around the interface between amorphous matrix and B2 phase as well as the deformation-induced twinning of B19' phase in vicinity of interface areas are occurred by occurrence of stress concentration around interface areas. Furthermore, these areas exhibit the higher hardness value than it of inside of B2 particles. Therefore, the hardening of the $\mathrm{B} 2$ phases related to stress-induced martensitic transformation and deformation twinning generate work-hardening phenomenon in Ti-based BMGC during deformation, which is very important to understand the mechanical behavior of the Ti-based BMGCs.

\section{CONFLICT OF INTEREST}

No potential conflict of interest relevant to this article was reported.

\section{REFERENCES}

Das J, Pauly S, Boström M, Durst K, Göken M, and Eckert J (2009) Designing bulk metallic glass and glass matrix composites in martensitic alloys. J. Alloys Compd. 483, 97-101.

Das J, Tang M B, Kim K B, Theissmann R, Baier F, Wang W H, and Eckert J (2005) "Work-Hardenable" ductile bulk metallic glass. Phys. Rev. Lett. 94, 205501.

Fan C, Li H Q, Kecskes L J, Tao K X, Choo H, Liaw P K, and Liu C T (2006) Mechanical behavior of bulk amorphous alloys reinforced by ductile particles at cryogenic temperatures. Phys. Rev. Lett. 96, 145506.

Fan C, Ott R T, and Hufnagel T C (2002) Metallic glass matrix composite with precipitated ductile reinforcement. Appl. Phys. Lett. 81, 10201022.

Gargarella P, Pauly S, Samadi Khoshkhoo M, Kühn U, and Eckert J (2014) Phase formation and mechanical properties of Ti-Cu-Ni-Zr bulk metallic glass composites. Acta Mater. 65, 259-269.

Greer A L (1995) Metallic glasses. Science 267, 1947-1953.
Hays C C, Kim C P, and Johnson W L (2000) Microstructure controlled shear band pattern formation and enhanced plasticity of bulk metallic glasses containing in situ formed ductile phase dendrite dispersions. Phys. Rev. Lett. 84, 2901-2904.

Hofmann D C, Suh J Y, Wiest A, Duan G, Lind M L, Demetriou M D, and Johnson W L (2008a) Designing metallic glass matrix composites with high toughness and tensile ductility. Nature 451, 1085-1089.

Hofmann D C, Suh J Y, Wiest A, Lind M L, Demetriou M D, and Johnson W L (2008b) Development of tough, low-density titanium-based bulk metallic glass matrix composites with tensile ductility. Proc. Natl. Acad. Sci. U S A 105, 20136-20140.

Hollomon J H (1945) Tensile deformation. Trans. AIME 162, 268-290.

Hong S H, Kim J T, Lee M W, Park J M, Lee M H, Kim B S, Park J Y, Seo Y, Suh J Y, Yu P, Qian M, and Kim K B (2014) Combinatorial influence of bimodal size of B2 TiCu compounds on plasticity of Ti-Cu-Ni-Zr-SnSi bulk metallic glass composites. Metall. Mater. Trans. A 45, 23762381. 
Inoue A, Shen B, Koshiba H, Kato H, and Yavari A R (2003) Cobalt-based bulk glassy alloy with ultrahigh strength and soft magnetic properties. Nature Mater. 2, 661-663.

Inoue A and Takeuchi A (2011) Recent development and application products of bulk glassy alloys. Acta Mater. 59, 2243-2267.

Kim J T, Hong S H, Lee C H, Park J M, Kim T W, Lee W H, Yim H I, and Kim K B (2014) Plastic deformation behavior of Fe-Co-B-Si-Nb-Cr bulk metallic glasses under nanoindentation. J. Alloys Compd. 587, 415419.

Kim K B, Das J, Venkataraman S, Yi S, and Eckert J (2006b) Work hardening ability of ductile Ti45Cu40Ni7.5Zr5Sn2.5 and Cu47.5Zr47.5Al5 bulk metallic glasses. Appl. Phys. Lett. 89, 071908.

Kim K B, Das J, Wang X D, Zhang X, Eckert J, and Yi S (2006a) Effect of $\mathrm{Sn}$ on microstructure and mechanical properties of (Ti-Cu)-based bulk metallic glasses. Philos. Mag. Lett. 86, 479-486.

Kim K B, Zhang X F, Yi S, Lee M H, Das J, and Eckert J (2008) Effect of local chemistry, structure and length scale of heterogeneities on the mechanical properties of a Ti45Cu40Ni7.5Zr5Sn2.5 bulk metallic glass. Philos. Mag. Lett. 88, 75-81.

Lee C H, Kim J T, Hong S H, Song G A, Jo J H, Moon S C, and Kim K B (2014a) Investigation of the mechanical properties of Ti-Fe-Sn ultrafine eutectic composites by dendrite phase selection. Met. Mater. Int. 20, 417-421.

Lee J K, Kim H J, Kim T S, and Bae J C (2007) Plasticity in bulk metallic glass composites containing dual amorphous phases. Mater. Sci. Forum. 539, 2026-2030.

Lee S W, Kim J T, Hong S H, Park H J, Park J Y, Lee N S, Seo Y, Suh J Y, Eckert J, Kim D H, Park J M, and Kim K B (2014b) Micro-to-nanoscale deformation mechanisms of a bimodal ultrafine eutectic composite. Sci. Rep. 4, 6500.

Park J M, Han J H, Mattern N, Kim D H, and Eckert J (2012) Designing Zr-Cu-Co-Al bulk metallic glasses with phase separation mediated plasticity. Metall. Mater. Trans. A 43, 2598-2603.
Pauly S, Gorantla S, Wang G, Kühn U, and Eckert J (2010) Transformationmediated ductility in CuZr-based bulk metallic glasses. Nat. Mater. 9, 473-477.

Pauly S, Liu G, Wang G, Kühn U, Mattern N, and Eckert J (2009) Microstructural heterogeneities governing the deformation of Cu47.5Zr47.5Al5 bulk metallic glass composites. Acta Mater. 57, 5445-5453.

Qiao J W, Sun A C, Huang E W, Zhang Y, Liaw P K, and Chuang C P (2011) Tensile deformation micromechanisms for bulk metallic glass matrix composites: from work-hardening to softening. Acta Mater. 59, 41264137.

Schuh C A, Hufnagel T C, and Ramamurty U (2007) Mechanical behavior of amorphous alloys. Acta Mater. 55, 4067-4109.

Spaepen F (1977) A microscopic mechanism for steady state inhomogeneous flow in metallic glasses. Acta Metall. 25, 407-415.

Telford M (2004) The case for bulk metallic glass. Mater. Today 7, 36-43.

Tian L, Cheng Y Q, Shan Z W, Li J, Wang C C, Han X D, Sun J, and Ma E (2011) Approaching the ideal elastic limit of metallic glasses. Nature Comm. 3, 609.

Wu Y, Xiao Y H, Chen G L, Liu C T, and Lu Z P (2010) Bulk metallic glass composites with transformation-mediated work-hardening and ductility. Adv. Mater. 22, 2770-2773.

Zhang Z, Zhao W, Sun Q, and Li C (2006) Theoretical calculation of the strain-hardening exponent and the strength coefficient of metallic materials. J. Mater. Eng. Perf. 15, 19-22.

Zhang Z Y, Wu Y, Zhou J, Song W L, Cao D, Wang H, Liu X J, and Lu Z P (2013) Effects of $S n$ addition on phase formation and mechanical properties of TiCu-based bulk metallic glass composites. Intermetallics $\mathbf{4 2}$, 6876.

Zhu Z, Zhang H, Hu Z, Zhang W, and Inoue A (2010) Ta-particulate reinforced $Z$ r-based bulk metallic glass matrix composite with tensile plasticity. Scripta Mater. 62, 278-281. 